Please do not remove this page

RMIT

UNIVERSITY

\title{
The relationship between investigative interviewing experience and open-ended question usage
}

Powell, Martine; Hughes-Scholes, Carolyn; Smith, Rebecca; Sharman, Stefanie

https://researchrepository.rmit.edu.au/esploro/outputs/9921861827401341/filesAndLinks?institution=61RMIT_INST\&index=null

Powell, M., Hughes-Scholes, C., Smith, R., \& Sharman, S. (2014). The relationship between investigative interviewing experience and open-ended question usage. Police Practice and Research, 15(4), 1-10. https://doi.org/10.1080/15614263.2012.704170

Document Version: Accepted Manuscript

Published Version: https://doi.org/10.1080/15614263.2012.704170

Repository homepage: https://researchrepository.rmit.edu.au

(C) 2012 Taylor \& Francis

Downloaded On 2023/04/26 19:41:51 +1000

Please do not remove this page 
Thank you for downloading this document from the RMIT Research Repository.

The RMIT Research Repository is an open access database showcasing the research outputs of RMIT University researchers.

RMIT Research Repository: http://researchbank.rmit.edu.au/

\section{Citation:}

Powell, M, Hughes-Scholes, C, Smith, R and Sharman, S 2012, 'The relationship between investigative interviewing experience and open-ended question usage', Police Practice and Research, pp. 1-10.

See this record in the RMIT Research Repository at:

http://researchbank.rmit.edu.au/view/rmit:17507

Version: Accepted Manuscript

Copyright Statement: (c) 2012 Taylor \& Francis

Link to Published Version:

http://dx.doi.org/10.1080/15614263.2012.704170 
Running head: INTERVIEW EXPERIENCE

Revision submitted to Police Practice and Research: An International Journal 1 March, 2012

The relationship between investigative interviewing experience and open-ended question usage

Martine B. Powell*, Carolyn H. Hughes-Scholes, Rebecca Smith \& Stefanie J. Sharman, School of Psychology, Deakin University, Burwood, Australia

Keywords: investigative interviewing, police interviewing, child abuse investigation.

*Address for correspondence: Professor Martine Powell, School of Psychology, Deakin University, 221 Burwood Hwy, Burwood, 3125, Victoria, Australia. Tel: 61-3-9244-6106. 


\begin{abstract}
We present three studies examining the role of prior job experience in interviewing and interviewers' ability to learn open-ended questions during a training program. We predicted a negative relationship such that more experienced interviewers would perform worse after training than less experienced interviewers, and that (irrespective of baseline performance) the more experienced interviewers would improve the least during training. These predictions were made for two reasons. First, specific questions are commonly used in the workplace (i.e., open-ended questioning constitutes new learning). Second, experience in the use of specific questions potentially interferes with newly learned open-ended questions. Overall, our predictions were supported across different participant samples (including police officers specialised in child abuse investigation and social workers from the child protection area), time delays and modes of training. The results highlight the need for investment in ongoing investigative interviewing training commencing early during professionals’ careers, prior to the establishment of long term habits in the use of specific questions.
\end{abstract}


The relationship between investigative interviewing experience and open-ended question usage

\section{Background}

Children are usually crucial witnesses in cases of alleged abuse perpetrated against them. In order to obtain child witness reports that are accurate and admissible in court, investigative interviewers must rely on open-ended questions (i.e., questions that elicit an elaborate response without dictating what specific information is required, such as "Tell me what happened”). Open-ended questions are known to encourage children (even very young children and those with cognitive and language limitations) to provide the most elaborate, accurate and coherent details (Agnew \& Powell, 2004; Dent \& Stephenson, 1979; Feltis, Powell, Snow, \& Hughes-Scholes, 2010; Orbach \& Lamb, 2007; Sternberg et al., 1996). Further, because open-ended questions encourage witnesses to play an active role in the interview process, they enhance witnesses’ perceptions that they are being listened to and they reduce the negative consequences of interviewer bias (Eastwood \& Patton, 2002). This bias encourages interviewers to focus on the information that they are searching for and to ask questions containing details not already mentioned by the interviewee.

In recognition of the research supporting the use of open-ended questions, professionals across the globe (e.g., police and social workers) are now taught how to use these questions when they join specialist child abuse investigation units as well as during ongoing professional development training programs. Despite this training, however, there is poor use of open-ended questions in field interviews. Interviewers mostly ask specific questions, which are questions that dictate what specific details are required and/or which narrow the witness response options (Powell \& Snow, 2007), such as "What colour shirt was he wearing?” Less than $25 \%$ of information typically obtained from child witnesses is currently elicited with open-ended questions (Powell, Fisher, \& Hughes-Scholes, 2008a; 2008b). 
According to a recent US Department of Justice funded report, this reduces the chances of successful prosecution (Pipe et al., 2008).

So why is there poor adherence to open-ended questions? Until recently, we did not know the answer to this question because there had been relatively little research examining how expertise in interviewing is learned and sustained. Most prior research had merely demonstrated the ineffectiveness of training programs by comparing interviewers’ performances pre- and post-training and reporting negligible change (Powell, Fisher, \& Wright, 2005). Importantly, however, not all programs have been ineffective and researchers have recently been able to establish the broad elements of training that lead to improvements in interviewing performance that are sustained in the long term. Two of the most important elements that distinguish successful and non-successful programs are consistent practice and feedback over time, after the implementation of the initial training course. The importance of these elements in the investigative interviewing context has been demonstrated by an increase in interviewers' use of open-ended questions with the adoption of these elements and a decline in performance following a period of time when these techniques were not maintained (Lamb, Sternberg, Orbach, Esplin, \& Mitchell, 2002a; Lamb et al., 2002b; Orbach et al., 2000; Sternberg, Lamb, Orbach, Esplin, \& Mitchell, 2001). Unfortunately, training programs across the globe rarely include such ongoing practice and feedback (Powell, 2008).

\section{Introduction to the current studies}

The reason why many organisations do not allocate sufficient resources for ongoing practice and feedback is multifaceted. One issue (relevant to this paper) is that best-practice interviewing is still perceived within many organisations to be 'learned on the job’ by conducting actual evidential interviews and watching more experienced staff conduct these interviews in the workplace (Aarons, Powell, \& Browne, 2004; Guadagno, Powell, \& 
Wright, 2006; Wright \& Powell, 2006). The reality is that poor adherence to a narrative framework is a widespread problem and there are few role models within organisations who can demonstrate recommended questioning techniques (Powell, 2008). Indeed, trainers have noted (anecdotally) that those persons who have had considerable 'on the job’ experience are often given the role of supervising others and yet they are not necessarily competent interviewers (Lamb, 2010; Powell, 2010). When professionals’ perceptions are elicited about their difficulties in adhering to open-ended questions, a common complaint of experienced interviewers is that because specific (i.e., less effective) questions have been habitually used in the workplace they are particularly difficult to overcome (Powell et al., 2008b; Wright \& Powell, 2006). This explanation is consistent with a phenomenon known in human learning literature as proactive interference (Hay \& Jacoby, 1996; 1999; Jacoby, Debner, \& Hay, 2001).

Proactive interference refers to the forgetting of information due to interference from events or learning that occurred prior to the current learning activity. To illustrate, consider the following verbal learning experiment by Jacoby et al. (2001). Participants in this learning experiment were trained that a particular word appeared with one response the majority of the time (75\% of trials; e.g., ale-beer) and with another response the minority of the time (25\% of trials; e.g., ale-brew). They were also trained that other words appeared with two responses equally often (e.g., 50\% bed-sheet; 50\% bed-sleep). When the participants were given a later cued-recall test (e.g., ale-b_e_), they were more likely to recall the pairing that had been presented the majority of the time. In other words, the word "beer” interfered with participants' recall of the word "brew” and thus participants were more likely to rely on the habitual response "beer”.

Within the investigative interview context, proactive interference is demonstrated when past learning or practice in the use of specific questions inhibits an individual's potential to 
retain a newly learned (i.e., open-ended) form of questioning. As yet, however, the role of prior experience has not been examined within the context of learning how to conduct investigative interviews of children. Although Smith, Powell, and Lum (2009) correlated interview experience (along with a number of other variables) and open-ended question usage, any meaningful interpretation of the relationship was obscured by a potential confound between interview experience and the time since training was completed. The time difference between the training in open-ended questions and the simulated interview was not constant for all participants such that some participants had received training within 12 weeks previously and others had not. In such heterogeneous samples, recency of training accounts for most of the variance in interviewer performance (Smith et al., 2009). Further, most interviewers revert back to prior performance (specific question use) within several months post-training (see Powell et al., 2005, for review). There is little value in examining the role of prior experience after performance has returned to the level that it was at before training.

The current studies built on prior research by examining the role of interview experience on the effectiveness of training in the use of open-ended questions. Presuming that (a) specific questioning is commonplace in the field and (b) experience in conducting field interviews prior to training inhibits new learning in the use of open-ended questions, we sought to answer two questions. First, is there a negative association between interviewer performance and prior interviewing experience? Second, is the degree of learning open-ended questions during training (i.e., the difference in performance pre- and post-training) negatively associated with prior interviewing experience? If the answer to these questions is affirmative, this would send a strong message to those police organisations who still use experience in the field as a benchmark for interviewing expertise when assigning caseloads and supervision duties. 
Our first study measured interviewer performance (i.e., open-ended question usage) of a group of child abuse investigators immediately after they completed a refresher training course in investigative interviewing. This design allowed us to test the first hypothesis - that professionals with greater prior experience would be poorer interviewers post-training.

Method

\section{Participants}

Participants included 41 Australian police officers (14 male, 27 female), all employed in a unit responsible for investigating criminal allegations of alleged child abuse. Participants were invited individually by their supervisors to partake in the research. Participation was voluntary and all professionals approached agreed to be involved.

\section{Procedure}

The design and procedure were approved by the University Ethics Committee, as well as the managers of the participating organisation. All outcome measures and refresher training were conducted at a large multipurpose training facility. First, participants completed a brief demographic questionnaire where (among a range of background factors) they estimated the number of investigative interviews they conducted previously with children and adults using the following Likert scale; 0, 1, 3, 5, 10, 20, 30, 40, 50, 75, 100, 150, 200, 300, $>300$.

Next, the participants engaged in a five-hour training session in the use of open-ended questions. This included two hours of instruction followed by three hours of practice and feedback during mock interview (role play) exercises. Importantly, all participants received the same training program. The instruction session defined the terms 'open-ended question' and 'specific question', provided a rationale for using open-ended questions, described the main types of open-ended questions and provided exemplars of the questions (including the use of minimal encouragers). Each participant then engaged in two 15-minute practice 
sessions (where an actor played the role of the child) and they received expert feedback about how to improve their performance (see Powell et al., 2008b, for further details about how this was delivered). All participants then participated in an assessment interview- the measure we correlated with prior experience.

The assessment interviews were audio taped, stopped after 10 minutes each and were completed in small, isolated rooms at the training facility. Each interview involved a new case scenario (different from those used in the practice sessions) of between 60-80 words. Participants were given the case scenarios 5 minutes before commencement. These covered a range of abusive incidents, all involving a five- or six-year-old child. An example is as follows:

One night Jessica, a five-year-old girl, refused to go to the toilet before she went to bed. When her mother insisted she go, Jessica began to cry. When she asked why she was crying Jessica told her mother that the bad man was in the toilets. When she asked Jessica where she had seen the bad man in the toilets, Jessica told her mother that the bad man had been in the toilets at the swimming pool.

All interviewers were instructed to commence the interview at the substantive phase by asking “Tell me what you're here to talk about today” and to elicit detailed and accurate information about the alleged abusive event, using free-narrative format where possible. The role-play exercises were standardised such that the persons playing the role of the child in these interviews had been trained (according to criteria outlined in prior research: Powell et al., 2008a; 2008b) to respond in a consistent way. The response criteria related to the amount of information and details to give to various types of questions, as well as behaviours and mannerisms, language and vocabulary. Specifically, the persons playing the role of the child were required to provide a general disclosure in response to the initial invitation (e.g., "About Joe/About what Joe did”) and to respond when asked to provide information. These actors 
were also instructed to provide the majority of abuse-related details in response to openended (e.g., "Tell me everything that happened with Joe”, "You said earlier you were in the toilets with Joe. Tell me more about the part when you were in the toilets with Joe", "What else happened when you saw Joe?”), rather than specific, questions (e.g., “Who is Joe?”, “Where did you see Joe?”, “Did Joe touch you?”). Adherence to the role-play procedure was verified prior to the commencement of the study. Interviewers' performances in mock interviews are consistent with their performance in field interviews (Powell, Cavezza, Hughes-Scholes, \& Stoove, 2010).

All persons involved in the delivery of the training were unaware of the research questions being examined in this study or the profile of the participants recorded on the demographic questionnaire.

\section{Coding}

All assessment interviews were audio taped and transcribed verbatim for coding. The number of open-ended versus specific questions was tallied separately. Open-ended questions were defined as any question that encouraged an elaborate response without dictating what specific information the child needed to report and without introducing information not yet mentioned by the child (e.g., “Tell me everything that happened when Uncle Joe touched your rude spot”, “What happened after you played the tickling game?”). Any non-open question was classified as a specific question, which included specific cued-recall (e.g., 'Wh' questions) and yes/no questions.

All transcripts were coded by one researcher and $15 \%$ were coded by a second researcher who was not otherwise involved in the study. Inter-rater reliability, calculated as agreements/ (agreements + disagreements), was at least 90\% for open-ended and specific questions. All discrepancies were resolved and the codes allocated by the chief coder were retained for analysis. 


\section{Results}

Participants’ prior interviewing experience as well as their actual performance in the mock (assessment) interview were examined. The experience and background of the interviewers differed markedly. The mean (estimated) number of interviews previously conducted by participants ranged from 0 to over 300, $(M=213.85, S D=141.80)$.

Participants asked approximately 80 questions in the mock-interview completed immediately after training (instruction and practice sessions) $(M=79.6, S D=7.3)$. The proportion of open-ended questions that participants asked was $0.30(S D=0.14$, range $=0.08-0.59)$. A moderate negative correlation was found between the estimated total number of interviews conducted by participants prior to training and the proportion of open-ended questions used in the mock interview. As expected, greater experience in interviewing children was associated with less open-ended question usage, $r=-.531, p=.001$.

\section{STUDY 2}

The results of Study 1 provided initial support for a negative association between experience and interviewing performance. However, the conclusions we can draw are limited because the study did not account for differences in baseline performance in interviewing. It may be that the experienced interviewers learned the same amount in the course, but that their poorer performance post-training was attributed to lower baseline performance when entering the course. To support proactive inhibition theory, it needs to be demonstrated that the learning of new information was inhibited. Study 2 addressed this limitation by assessing performance pre-and post-training and correlating prior experience in interviewing with degree of change in interviewing performance from the pre- to post-assessment interview.

\section{Method}

The participants were 30 Australian police officers (12 male, 18 female) working in the area of child abuse investigation. The procedure was the same as the previous study 
except for two changes. First, all participants engaged in one additional assessment interview which was administered immediately prior to the training program. Note that a new scenario and actor was used in each interview (these were counterbalanced among the participants so that any change in performance could not be attributed to the particular scenario or actor). Second, because of the additional time required to stage the pre-training assessment sessions, the intensity of training was reduced. The training consisted of the 3-hour instruction only. It did not include the practice and feedback sessions.

\section{Results}

To calculate interviewer performance in each of the mock interviews, proportion scores were calculated for each of the pre-training and immediate post-training interviews by dividing the number of open-ended questions asked in the interview by the total number of questions. Next, the change in performance between the pre-training and immediate posttraining interview was calculated by subtracting the proportion of open-ended questions asked in the pre-training interview from the proportion asked in the immediate post-training interview. Initial analyses revealed that pre-training performance was not related to the years in service, $r=.334, p=.071$, or interviewer gender, $r=.071, p=.709$.

Similar to Study 1, the estimated number of prior interviews ranged from 0 to over $300(M=172.60, S D=126.20)$. Participants asked an average of 49 questions in the pretraining interview $(M=49.0, S D=19.0)$ and 37 questions in the post-training interview $(M=$ $37.2, S D=9.2$ ). The mean proportion of open-ended questions that participants asked in the pre- and post- training interview was $0.36(S D=0.20$, range $=0.06-0.96)$ and $0.52(S D=$ 0.19 , range $=0.14-1.00$ ) respectively. The mean difference in the proportion of open-ended questions that participants asked in the pre-training interview compared to the post-training interview was $0.15(S D=0.25$, range $=-0.38-0.58)$. A moderate negative correlation was found between the number of interviews participants had conducted prior to training and their 
change in open-ended question usage between the pre-training and post-training interviews, $r$ $=-.537, p=.002$. This correlation indicated that greater experience in interviewing was associated with less improvement in open-ended question usage between the pre-training and post-training interviews.

\section{STUDY 3}

The final analyses presented in this paper tested the generalisability of the prior findings in two ways. First, a different participant group was used (social workers instead of police officers). Further, there were two post-training assessment interviews, one held immediately after training (as in Studies 1 and 2) and one held 12 weeks later, when there had been no intervening training. Overall, we expected the negative correlation to extend across samples but not over time such that the negative correlation would only be evident at the initial assessment. As several prior studies suggest, most of the gains made in training are eliminated within three months when there has been no ongoing practice and feedback (see Powell et al., 2005, for review). As the effects of training should have reduced over time, we also expected that the negative correlation between experience and use of open-ended questions should have reduced over time.

\section{Method}

The participants were 27 social workers (19 male, 8 female) who were employed by a state child protection service in Australia. As with the previous studies, the sample of participants was heterogeneous in terms of background experience and length of service.

All of the participants in the current study conducted three mock interviews. As was the procedure in Study 2, the participants conducted a pre-training interview that involved each participant individually undertaking a 10-minute assessment interview with an actor playing the role of the child. This interview was followed by a 2-hour instruction session that focused on the use of open-ended questions. Next, the participants conducted the immediate 
post-training interview and again twelve weeks after the immediate post-training interview. All interviews were conducted in the same manner as the pre-training interviews except that the twelve-week follow-up interview (hereby referred to as the delayed assessment) were held individually at the participants’ workplace or by phone conference (for those participants who were based in rural areas).

\section{Results}

Participants’ prior interviewing experience and their change in performance from the pre-training interview to the immediate post-training and delayed follow-up interviews was examined. The estimated number of field interviews they had previously conducted ranged from one to over $300(M=46.51, S D=97.70)$. Initial analyses revealed that pre-training performance was not related to the number of interviews participants had conducted prior to training, $r=-.042, p=.835$, the years in service, $r=-.051, p=.801$, or interviewer gender, $r$ $=-.199, p=.320$.

Interviewers asked an average of 63 questions in the pre-training interview ( $M=62.7$, $S D=16.6)$; 31 questions in the immediate post-training interview $(M=30.7, S D=13.6)$, and 32 questions in the delayed assessment interview $(M=32.4, S D=19.1)$. The mean proportion of open-ended questions that participants asked in the pre-training interview was $0.15(S D=0.13$, range $=0.00-0.53)$ compared to $0.67(S D=0.23$, range $=0.20-0.96)$ in the immediate post-training interview and $0.82(S D=0.13$, range $=0.56-1.00)$ in the delayed assessment interview. The mean difference in the proportion of open-ended questions that participants used in the pre-training interview compared to the immediate post-training interview was $0.52(S D=0.25$, range $=0.08-0.90)$. A moderate negative correlation was found between the number of interviews conducted by participants prior to training and change in open-ended question usage between the pre-training and immediate post-training interviews, $r=-.490, p=.009$. 
The mean difference in the proportion of open-ended questions that participants used in the pre-training interview compared to the delayed assessment interview was 0.36 ( $S D=$ 0.28 , range $=-0.13-0.89$ ). A moderate negative correlation was found between the number of interviews conducted by participants and change in open-ended question usage between the pre-training and delayed assessment interviews, $r=-.453$, $p=.018$. Consistent with the previous studies, the more experience participants had in interviewing the less improvement in open-ended question usage between the pre-training and post-training interviews.

\section{GENERAL DISCUSSION}

This research has presented robust evidence in support of a negative association between prior interview experience and adherence to best-practice guidelines among investigative interviewers of children. Specifically, we showed that the more investigative interviewing experience professionals had prior to training, the fewer open-ended questions they used when assessed immediately after training. The findings were consistent across participant samples, time delays and modes of training, and should be considered within the context that investigative interviewers habitually use a different style of questioning (predominantly specific questions - which was evident at the baseline interviews) than that taught in the training programs.

Overall, the findings are consistent with proactive interference theory. This theory suggests that interviewers' prior use of specific questions interfered with their ability to learn the new style of questioning during our training course (Brown, 1976; Crowder, 1976; Hay \& Jacoby, 1996, 1999). There are several aspects of our data that support this interpretation. First, prior experience in interviewing showed a significant negative correlation with performance post-training, as well as the amount of improvement (i.e., learning) exhibited during the training program. Second, several post-analyses revealed that the findings were consistent irrespective of whether the independent measure was years in service (an objective 
measure of experience) as opposed to estimated number of prior interviews (a subjective measure $)^{1}$.

Further, independent research has indicated that the observed change in performance across the assessments would have been attributable to training rather than increased familiarity with the role play exercises per se. In a study using a similar sample and assessment paradigm we showed that interviewer performance is relatively stable over time without intervening training practice and feedback (see Powell, Hughes-Scholes, Cavezza, \& Stoove, 2010). Further, when we repeated Study 2 but without any intervening training at all, we found no significant correlation between interview experience and change in open-ended question usage between Assessment time 1 and $2(r=-.016, p=.914)^{2}$.

One potential limitation of the current studies needs to be addressed. We relied on participants' estimates of their number of interview experiences, rather than having an objective measure of their number of interviews. However, there was a significant positive correlation between participants' years of service and the number of prior interviewers that they reported, which suggests that their estimates reflected their actual interview experiences.

\section{Conclusion}

The importance of the current findings should not be underestimated. Although there has been a great deal of discussion about the importance of ongoing practice and feedback and of introducing training at the early recruit stage prior to the development of 'bad habits' (Powell et al., 2005; Powell, 2008; Griffiths \& Milne, 2005), there has been relatively little empirical research to support these recommendations. Indeed, this is the first study to demonstrate that prior interview experience can shape interviewers' abilities to change performance through training. The current research clearly disputes the myth in police

\footnotetext{
${ }^{1}$ The correlation between years of service and prior interviews is $r=.504, p<.001$.

${ }^{2}$ Data for this study can be supplied on request.
} 
organisations that the senior or more experienced interviewers are in the best position to supervise new staff and that a one-size training model fits all trainee interviewers. For organisations to get any return on the substantial investments made in investigative interview training, training needs to be delivered early in the professionals' careers and there needs to be on ongoing practice and quality control evaluation in the form of feedback that is regularly delivered. In other words, experience is important but the type of experience needs to be considered. Once open-ended questioning is more commonplace in the field, we may well see a change in the relationship such that experience on the job (through observing others in the workplace) plays a more positive constructive role. 


\section{Acknowledgements}

Thank you to all of those who participated in the study and to Rebecca Steinberg for her editorial assistance. This research was supported, in part, by an Australian Research Council Linkage Grant (LP0775248). 
Notes on contributors

Martine Powell is Professor of Psychology, Deakin University. For the past 18 years, she has conducted research on child eyewitness memory and investigative interviewing and has played a major role in the design and implementation of interviewer training programs throughout Australia.

Carolyn Hughes-Scholes is a Research Fellow in the School of Psychology, Deakin University. Dr Hughes-Scholes has been a researcher in the area of children's eyewitness testimony and police interviewing for the past 12 years.

Rebecca Smith is a Forensic Doctoral Student in the School of Psychology, Deakin University. Her thesis examines individual and background factors (apart from training) that may predict interview performance.

Stefanie Sharman is a Lecturer in the School of Psychology at Deakin University. She has over 14 years' experience using experimental methods to investigate people’s memories for past personal experiences. 


\section{References}

Aarons, N. M., Powell, M. B., \& Browne, J. (2004). Police perceptions of interviews involving children with intellectual disabilities: A qualitative inquiry. Policing and Society, 14, 269-278.

Agnew, S. E., \& Powell, M. B. (2004). The effect of intellectual disability on children’s recall of an event across different question types. Law and Human Behavior, 28, 273294.

Brown, A. S. (1976). Spontaneous recovery in human learning. Psychological Bulletin, 83, 321-328.

Crowder, R. G. (1976). Principles of learning and memory. NJ: Erlbaum.

Dent, H. R., \& Stephenson, G. M. (1979). An experimental study of the effectiveness of different techniques of questioning child witnesses. British Journal of Social and Clinical Psychology, 18, 41-51.

Eastwood, C., \& Patton, W. (2002). The experiences of child complainants of sexual abuse in the criminal justice system, Report to the Criminology Research Council, Canberra, http://www.aic.gov.au/crc/reports/eastwood.html.

Feltis, B. B., Powell, M. B., Snow, P. C., \& Hughes-Scholes, C. H. (2010). An examination of the association between interviewer question type and story-grammar detail in child witness interviews about abuse. Child Abuse \& Neglect, 34, 407-413.

Griffiths, A., \& Milne, B. (2005). Will it all end in tiers? Police interviews with suspects in Britain. In T. Williamson (Ed.), Investigative interviewing: Rights, research, regulation (pp. 167-189). Cullompton: Willan Publishing.

Guadagno, B., Powell, M. B., \& Wright, R. (2006). Police officers’ and legal professionals’ perceptions regarding how children are, and should be, questioned about repeated abuse. Psychiatry, Psychology \& Law, 13(2), 251-260. 
Hay, J. F., \& Jacoby, L. L. (1996). Separating habit and recollection: Memory slips, process dissociations and probability matching. Journal of Experimental Psychology: Learning, Memory, and Cognition, 22, 1323-1335.

Hay, J. F., \& Jacoby, L. L. (1999). Separating habit and recollection in young and elderly adults: Effects of elaborative processing and distinctiveness. Psychology and Aging, $14,122-134$.

Jacoby, L. L., Debner, J. A., \& hay, J. F. (2001). Proactive interference, accessibility bias, and process dissociations: valid subjective reports of memory. Journal of Experimental Psychology: Learning, Memory, and Cognition, 27, 686-700.

Lamb, M. B. (2010). Investigative Interviewing of child witnesses. Masterclass lecture $3^{\text {rd }}$ Annual conference of the International Investigative Interviewing research group, 2224 June 2010, Stavern Norway.

Lamb, M. E., Sternberg, K. J., Orbach, Y., Esplin, P. W., \& Mitchell, S. (2002a). Is ongoing feedback necessary to maintain the quality of investigative interviews with allegedly abused children? Applied Developmental Science, 6, 35-41.

Lamb, M. E., Sternberg, K. J., Orbach, Y., Hershkowitz, I., Horowitz, D., \& Esplin, P. W. (2002b). The effects of intensive training and ongoing supervision on the quality of investigative interviews with alleged sex abuse victims. Applied Developmental Science, 6, 114-125.

Orbach, Y., Hershkowitz, I., Lamb, M. E., Sternberg, K. J., Esplin, P. W., \& Horowitz, D. (2000). Assessing the value of structured protocols for forensic interviews of alleged child abuse victims. Child Abuse and Neglect, 24, 733-752.

Orbach, Y., \& Lamb, M. E. (2007). Young children's references to temporal attributes of allegedly experienced events in the course of forensic interviews. Child Development, 78, 1100-20. 
Pipe, M-E., Orbach, Y., Lamb, M., Abbott, C. B., \& Stewart, H. (2008). Do best practice interviews with child abuse victims influence case processing? Final report submitted to the U.S. Department of Justice, Award Number 2006-IJ-CX-0019.

Powell, M. B. (2008). Designing effective training programs for investigative interviewers of children. Current Issues in Criminal Justice, 20, 189-208.

Powell, M. B. (2010). Guide to designing effective training programs in the area of investigative interviewing of children (Keynote address). $3^{\text {rd }}$ Annual Conference of the International Investigative Interviewing Research Group (iIIRG), Norwegian Police University College, Norway, 22-24 June, 2010.

Powell, M. B., Cavezza, C., Hughes-Scholes, C. H., \& Stoove, M. A. (2010). Examination of the consistency of interviewer performance across three distinct interview contexts. Psychology, Crime \& Law, 16, 585 - 600.

Powell, M. B., Fisher, R. P., \& Hughes-Scholes, C. H. (2008a). The effect of intra- versus post-interview feedback during simulated practice interviews about child abuse. Child Abuse \& Neglect, 32, 213-227.

Powell, M. B., Fisher, R. P., \& Hughes-Scholes, C. H. (2008b). The effect of using trained versus untrained adult respondents in simulated practice interviews about child abuse. Child Abuse \& Neglect, 32, 1007-1016.

Powell, M. B., Fisher, R. P., \& Wright, R. (2005). Investigative interviewing. In N. Brewer \& K. Williams (Eds.), Psychology and law: An empirical perspective (pp. 11-42). New York: Guilford.

Powell, M. B., Hughes-Scholes, C., Cavezza, C. \& Stoove, M. (2010). Examination of the stability and consistency of investigative interviewer performance. Legal and Criminological Psychology, 15, 243-260.

Powell, M. B., \& Snow, P. C. (2007). Guide to questioning children during the freenarrative phase of an investigative interview. Australian Psychologist, 42, 57-65. 
Smith, R. M., Powell, M. B., \& Lum, J. (2009). The relationship between job status, interviewing experience, gender and police officers’ adherence to open-ended questions. Legal and Criminological Psychology, 14, 51-63.

Sternberg, K. J., Lamb, M. E., Esplin, P. W., Orbach, Y., \& Mitchell, S. (2001). Use of a structured investigative protocol enhances young children's responses to free-recall prompts in the course of forensic interviews. Journal of Applied Psychology, 86, 9971005.

Sternberg, K. J., Lamb, M. E., Hershkowitz, I., Esplin, P. W., Redlich, A., \& Sunshine, N. (1996). The relation between investigative utterance types and the informativeness of child witnesses. Journal of Applied Developmental Psychology, 17, 439-451.

Wright, R., \& Powell, M. B. (2006). Investigative interviewers’ perceptions of their difficulty in adhering to open-ended questions with child witnesses. International Journal of Police Science \& Management, 8, 316-325. 